\title{
YKL-40 is a local marker for inflammation in patients with pseudoexfoliation syndrome
}

\author{
Tansu Gonen ${ }^{1} \cdot$ Savas Guzel ${ }^{2}$ - Kadircan H. Keskinbora ${ }^{3}$
}

Received: 11 December 2017 / Revised: 7 September 2018 / Accepted: 17 October 2018 / Published online: 18 December 2018

(c) The Royal College of Ophthalmologists 2018

\begin{abstract}
Purpose To investigate the YKL-40, as a marker of inflammation, in aqueous humor and serum of cataract patients with and without pseudoexfoliation syndrome (PEX).

Methods Aqueous humor and serum samples were obtained from 44 patients who underwent phacoemulsification surgery. All patients were divided into two groups: PEX $(n=24)$ and control $(n=20)$. YKL-40 levels were measured with enzymelinked immunosorbent assay (ELISA). The differences between the groups were assessed by using Chi-square and independent sample $t$-tests. The Pearson correlation coefficient was used to evaluate the correlation between variables.

Results There was a significant difference between the mean YKL-40 levels in the aqueous humor of PEX group (112.0 \pm $35.8 \mathrm{ng} / \mathrm{mL})$ and control subjects $(88.2 \pm 30.6 \mathrm{ng} / \mathrm{mL})(P=0.025)$. However, the difference between the mean YKL-40 levels in the serum of PEX group $(53.5 \pm 29.1 \mathrm{ng} / \mathrm{mL})$ and control subjects $(44.6 \pm 30.2 \mathrm{ng} / \mathrm{mL})$ was non-significant $(P=$ 0.326). The correlation between aqueous humor and serum YKL-40 concentrations was significant in both the groups $(r=$ $0.833, P<0.001 ; r=0.840, P<0.001$, respectively).

Conclusions Increased aqueous humor levels of YKL-40 demonstrate that it is local, but not a systemic marker for inflammation in patients with PEX.
\end{abstract}

\section{Introduction}

Pseudoexfoliation syndrome (PEX) is a common, agerelated, generalized disorder of the extracellular matrix that is characterized by production and accumulation of an abnormal fibrillar extracellular material in ocular and extraocular tissues including skin, connective tissue portions of various visceral organs, aorta, and peripheral arteries [1,2]. Chronic intraocular pressure elevation and glaucoma development, poor pupillary dilation, and zonular weakness are the most common ocular manifestations of PEX. Intraocular exfoliation material seems to be produced

Tansu Gonen

tansugonen@yahoo.com

1 Tekirdag Namik Kemal University, School of Medicine, Department of Ophthalmology, Tekirdag, Turkey

2 Tekirdag Namik Kemal University, School of Medicine, Department of Biochemistry, Tekirdag, Turkey

3 Bahcesehir University, School of Medicine, Department of Medical Ethics and History of Medicine, Istanbul, Turkey in the pre-equatorial lens epithelium, non-pigmented ciliary epithelium, iris pigment epithelium, corneal endothelium, trabecular endothelium, and by almost all cell types of the iris stroma [1]. Proinflammatory cytokines participate in the initiation of the local inflammation that is caused by oxidative stress and anterior chamber hypoxia, and increased expression of these cytokines may act as a triggering factor for the abnormal exfoliation material production in the early stages of this fibrotic process [3-6].

YKL-40 is a $40-\mathrm{kDa}$ heparin- and chitin-binding glycoprotein and is also known as human cartilage glycoprotein 39 (HCgp39), 38-kDa heparin-binding glycoprotein or chitinase-3-like protein 1 (CHI3L1) glycoprotein, and is thought to have a role in acute and chronic inflammation, extracellular matrix remodeling, innate immune response, angiogenesis, atherosclerosis, and endothelial dysfunction. In patients with systemic infection, inflammatory disorders, and cancer, serum levels of YKL-40 are increased [7-12]. Both monocytes/macrophages, neutrophils, and cancer cells have the capacity to produce YKL-40 [13].

The role of inflammation in PEX pathogenesis is an important issue. YKL-40 is an inflammatory biomarker and is used in the monitoring of systemic vascular and 
inflammatory diseases [12, 14-18]. In aqueous humor, YKL-40 has not been investigated in patients with PEX previously. This study was conducted to determine the YKL-40 levels in aqueous humor and serum of cataract patients with and without PEX undergoing phacoemulsification.

\section{Materials and methods}

In this prospective case-control study, a total of 44 aqueous humor and serum samples were collected from 24 patients who had senile cataract with PEX (PEX group) and 20 patients who had senile cataract without PEX (control group). Patients with inflammatory ophthalmic diseases, such as keratitis, uveitis, scleritis, a history of trauma, PEX glaucoma, intraocular surgery, cryotherapy or laser photocoagulation, and systemic diseases, such as cardiovascular (except well-controlled systemic hypertension) and cerebrovascular diseases, peripheral arterial diseases, diabetes mellitus, taking any topical and systemic medications (except systemic antihypertensive treatment) that might have influenced the aqueous humor and serum level of YKL-40, chronic renal failure, liver diseases, history of malignancies, hypercholesterolemia, smoking, and consumption of alcohol were excluded from the study. The study protocol was approved by the local Ethics Committee of the University of Tekirdag Namik Kemal and performed according to the Helsinki declaration. Written informed consent was obtained from all participant subjects.

Each patient underwent a complete ocular examination prior to surgery, including slit lamp biomicroscopy, funduscopy, intraocular pressure measurement by applanation tonometry, gonioscopy, and visual field testing using Humphrey Field Analyzer (if applicable). The observation of typical exfoliative material on the anterior lens capsule after pupillary dilation with tropicamide $1 \%$ and pupillary margin was defined as PEX. The subjects of PEX group were considered as early PEX without major dilatation deficit.

\section{Aqueous humor and blood sampling}

At the beginning of phacoemulsification, 50 to $100 \mu \mathrm{L}$ of aqueous humor was aspirated through clear corneal paracentesis using a 27-gauge needle attached to a tuberculin syringe. Meticulous care was taken to avoid touching the iris, lens, corneal endothelium, and conjunctiva and to prevent contamination of the sample from balanced salt solution, blood, and povidone iodine. All surgeries were completed successfully. Serum samples were also obtained from patients before cataract surgery after an overnight fasting. The concentrations of serum glucose, C-reactive protein (CRP), fibrinogen, triglyceride, total cholesterol, low-density lipoprotein (LDL), and high-density lipoprotein (HDL) were analyzed after sampling. For YKL-40 analysis, $5 \mathrm{~mL}$ of forearm venous blood was collected in tubes without any anticoagulant. The blood and aqueous humour samples were immediately centrifuged at $1000 \mathrm{~g}$ for 5 minutes at $4{ }^{\circ} \mathrm{C}$ and transported to the laboratory within $2 \mathrm{~h}$ to be stored as supernatant at $-80{ }^{\circ} \mathrm{C}$ until required for analysis.

\section{YKL-40 analysis}

YKL-40 levels in the samples were quantified by Uscn Life Science (Glycoprotein 39 (GP39), SEB463Ra, Wuhan, China) enzyme-linked immunosorbent assays (ELISAs). The minimum detectable dose of human YKL-40 is typically less than $1.22 \mathrm{ng} / \mathrm{mL}$.

\section{Statistical analysis}

Statistical analysis was performed with SPSS for Windows 22.0 (Statistical Product and Service Solutions, Inc., Chicago, IL, USA) package program. The normality of the data was confirmed using the Shappiro-Wilk test. In descriptive analysis, the measurement variables are given as a mean \pm standard error. The differences between groups were assessed by using chi-square and independent sample $t$ tests. The Pearson correlation coefficient was used to evaluate the correlation between variables. $P$ values of less than 0.05 were considered statistically significant.

\section{Results}

For both the groups, demographics and laboratory results are summarized in Table 1. No difference was observed between the groups with regard to age, sex, serum levels of glucose, C-reactive protein, fibrinogen, triglyceride, total cholesterol, low-density lipoprotein, and high-density lipoprotein $(P>0.05)$. Ten patients of PEX group and nine of control group had well-controlled systemic hypertension. The difference between groups was not significant $(P=$ $0.824)$. There was a significant difference in aqueous humor levels of YKL-40 between PEX and control groups $(P=$ $0.025)$. On the other hand, the difference in serum levels of YKL-40 between PEX and control groups was not significant $(P=0.326)$ (Fig. 1). A significant positive linear correlation between aqueous humor and serum YKL-40 
Table 1 Demographics and laboratory results

\begin{tabular}{llll}
\hline & PEX group & Control group & $P$ value \\
\hline Age, years & & & 0.129 \\
Mean \pm SD & $75.6 \pm 5.2$ & $72.8 \pm 6.9$ & \\
Range & $65-84$ & $65-90$ & \\
Sex, $n(\%)$ & & & 0.263 \\
Male & $16(66.7)$ & $10(50)$ & \\
Female & $8(33.3)$ & $10(50)$ & \\
Hypertension, $n(\%)$ & $10(41.6)$ & $9(45)$ & 0.824 \\
Serum glucose (mg/dL) & $92.5 \pm 15.0$ & $100.7 \pm 20.4$ & 0.622 \\
CRP (mg/L) & $3.0 \pm 2.4$ & $2.9 \pm 2.0$ & 0.831 \\
Fibrinogen (mg/dL) & $350.7 \pm 85.6$ & $386.4 \pm 74.9$ & 0.211 \\
Triglyceride (mg/dL) & $127.0 \pm 46.8$ & $144.3 \pm 43.2$ & 0.228 \\
Total cholesterol (mg/dL) & $190.2 \pm 19.7$ & $189.5 \pm 23.9$ & 0.935 \\
LDL (mg/dL) & $110.0 \pm 14.0$ & $109.1 \pm 16.6$ & 0.893 \\
HDL (mg/dL) & $44.6 \pm 9.5$ & $48.1 \pm 10.0$ & 0.300 \\
YKL-40 (ng/mL) & & & \\
Aqueous humour & $112.0 \pm 35.8$ & $88.2 \pm 30.6$ & $\mathbf{0 . 0 2 5}$ \\
Serum & $53.5 \pm 29.1$ & $44.6 \pm 30.2$ & 0.326 \\
\hline$P E X$ pseudoexfor & & &
\end{tabular}

PEX pseudoexfoliation syndrome, CRP C-reactive protein, $L D L$ lowdensity lipoprotein, $H D L$ high-density lipoprotein

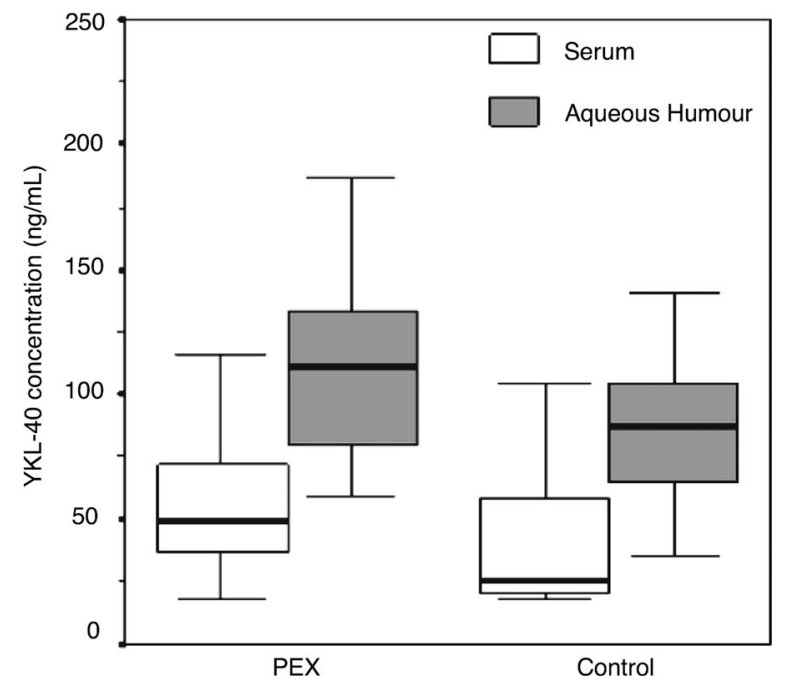

Fig. 1 Box plotshowing aqueous humour and serum YKL-40 levels in patients with PEX $(n=24)$ and controls $(n=20)$. Middle horizontal line inside box indicates the 50th percentile or median. Bottom and top of the box are 25 th and 75 th percentiles, respectively

levels was demonstrated in both the groups $(r=0.833$ and $P<0.001 ; r=0.840$ and $P<0.001$, respectively). The correlations between YKL-40 and other laboratory test values were not significant (Table 2). There was no correlation between age and aqueous humor and serum YKL-40 levels in PEX and control groups $(r=0.059$ and $P=0.790 ; r=$ 0.035 and $P=0.872 ; r=-0.207$ and $P=0.395 ; r=$ -0.013 and $P=0.956$, respectively).
Table 2 Correlations between laboratory parameters and YKL-40

\begin{tabular}{|c|c|c|c|c|}
\hline \multirow{2}{*}{$\begin{array}{l}\text { Laboratory } \\
\text { parameters }\end{array}$} & \multicolumn{2}{|c|}{ PEX group } & \multicolumn{2}{|c|}{ Control group } \\
\hline & $\begin{array}{l}\text { Aqueous } \\
\text { humour }\end{array}$ & Serum & $\begin{array}{l}\text { Aqueous } \\
\text { humour }\end{array}$ & Serum \\
\hline \multicolumn{5}{|c|}{ Serum glucose } \\
\hline$r$ value & 0.260 & 0.234 & -0.307 & -0.475 \\
\hline$P$ value & 0.499 & 0.514 & 0.308 & 0.086 \\
\hline \multicolumn{5}{|l|}{ Fibrinogen } \\
\hline$r$ value & 0.337 & 0.283 & -0.534 & 0.088 \\
\hline$P$ value & 0.135 & 0.202 & 0.060 & 0.765 \\
\hline \multicolumn{5}{|l|}{ Triglyceride } \\
\hline$r$ value & -0.171 & -0.060 & -0.050 & -0.223 \\
\hline$P$ value & 0.470 & 0.796 & 0.838 & 0.345 \\
\hline \multicolumn{5}{|c|}{ Total cholesterol } \\
\hline$r$ value & 0.261 & 0.344 & -0.246 & -0.360 \\
\hline$P$ value & 0.413 & 0.250 & 0.358 & 0.156 \\
\hline \multicolumn{5}{|l|}{$H D L$} \\
\hline$r$ value & -0.059 & -0.235 & -0.360 & -0.262 \\
\hline$P$ value & 0.815 & 0.333 & 0.143 & 0.279 \\
\hline \multicolumn{5}{|l|}{$L D L$} \\
\hline$r$ value & -0.153 & 0.006 & -0.426 & -0.450 \\
\hline$P$ value & 0.654 & 986 & 0.088 & 0.061 \\
\hline \multicolumn{5}{|l|}{$C R P$} \\
\hline$r$ value & 0.227 & 0.287 & -0.016 & 0.248 \\
\hline$P$ value & 0.337 & 0.207 & 0.954 & 0.336 \\
\hline
\end{tabular}

$P E X$ pseudoexfoliation syndrome, $C R P$ C-reactive protein, $L D L$ lowdensity lipoprotein, $H D L$ high-density lipoprotein

\section{Discussion}

In this study, we measured aqueous humor and serum YKL40 levels as an inflammation marker in patients with PEX. The act of inflammatory molecules in PEX pathophysiology is a substantial research topic. There are recent studies showing the relationship between PEX and inflammation [5, 19-22]. Systemic inflammatory markers, such as CRP and fibrinogen, are produced by the liver in response to proinflammatory cytokines that are generated locally or systemically following acute inflammation [23]. The cells of the immune system, vascular endothelial cells, and smooth and striated muscle cells are the major sources of proinflammatory cytokines, such as interleukin (IL)-6 and IL-8 [24]. Another source of IL-6 is the cells of the iridal vascular endothelium and those of the non-pigmented ciliary epithelium [5]. These cytokines are frequently used to evaluate intraocular and systemic inflammation in patients with PEX [13, 19-21, 25]. YKL-40 is a well-known locally produced and released glycoprotein in relation to proinflammatory cytokines in the pathogenesis of inflammation [13, 16-18]. In response to increased serum levels 
of IL-6, that is able to stimulate YKL-40 release, serum levels of YKL-40 increase [13].

In various diseases affecting the cardiovascular system, increased serum YKL-40 levels were observed. Some laboratory parameters, such as high sensitivity CRP, fasting/ postprandial triglyceride, and fasting glucose, which are risk factors for vascular diseases, also show a significant correlation with YKL-40 [12, 14, 15, 26-28]. In previous studies, association between PEX and systemic vascular disease, such as atherosclerosis, hypertension, myocardial infarction, aneurysms of the abdominal aorta, and stroke were revealed [29-32]. The similarities between PEX and YKL-40 in relation to systemic vascular disease, as well as in the involvement of local and systemic inflammatory processes are the conditions that support to the analysis of the possible links between them. In a recent study, the authors said that elevated serum YKL-40 level is a new potential biomarker of inflammation and vascular dysfunction in patients with PEX [33]. Unlike our study, they did not exclude patients who had systemic inflammatory and vascular diseases and possible risk factors for those diseases and the YKL-40 analysis were only performed in the serum samples. In our study, normal serum YKL-40, fibrinogen, and CRP values exclude the systemic inflammation and high aqueous humor levels of YKL-40 indicate that it participates locally in the pathogenesis of inflammation in patients with early stages of PEX. The serum levels of YKL-40 may increase with progression of PEX and/or with the participation of PEX-related systemic diseases in the process.

Some studies say that YKL-40 level increases with age and it is necessary to make an age correction, others say the contrary [34-36]. Moreover, YKL-40 levels are not affected diurnally, weekly, or by long-term variation in healthy subjects, and physical exercise has no effect on the serum level of YKL-40 [36]. There is no significant difference in serum or plasma YKL-40 concentrations between gender [17]. No relationship was observed between aqueous humor YKL-40 levels and age and gender in the control and PEX groups in this study. Some medicines, such as etanercept, quercetin, and metformin reduce serum YKL-40 levels, while dexsamethasone and resveratrol block YKL-40 expression in vitro [37-41]. Estrogens reduce YKL-40 production in the retina [42]. For this reason, this study excluded patients who used any medicines other than antihypertensives. Our study has some limitations. First, the levels of the cytokines in aqueous humor were not measured. The relation between YKL-40 and those cytokines was established based on the previous reports. Second, the sample size of this study is relatively small.

In conclusion, increased aqueous humor and normal serum YKL-40 levels show that YKL-40 is a local, but not a systemic marker for inflammation in patients with PEX.
This may contribute to understand pathophysiologically process associated with inflammation in PEX. Further studies are needed to clarify its benefit as a prognostic marker and to confirm our findings.

\section{Summary}

\section{What was known before}

$\checkmark$ YKL-40 is a marker for the systemic inflammatory diseases.

\section{What this study adds}

$\checkmark$ YKL-40 is a local marker in patients with pseudoexfoliation syndrome.

\section{Compliance with ethical standards}

Conflict of interest The authors declare that they have no conflict of interest.

Publisher's note: Springer Nature remains neutral with regard to jurisdictional claims in published maps and institutional affiliations.

\section{References}

1. Ritch R, Schlötzer-Schrehardt U. Exfoliation syndrome. Surv Ophthalmol. 2001;45:265-315.

2. Streeten BW, Li ZY, Wallace RN, Eagle RC Jr, Keshgegian AA. Pseudoexfoliative fibrillopathy in visceral organs of a patient with pseudoexfoliation syndrome. Arch Ophthalmol. 1992;110:175762.

3. Helbig H, Schlötzer-Schrehardt U, Noske W, Kellner U, Foerster $\mathrm{MH}$, Naumann GOH. Anterior-chamber hypoxia and iris vasculopathy in pseudoexfoliation syndrome. Ger J Ophthalmol. 1994;3:148-53.

4. Schlötzer-Schrehardt U. Oxidative stress and pseudoexfoliation glaucoma. Klin Monbl Augenheilkd. 2010;227:108-13.

5. Zenkel M, Lewczuk P, Jünemann A, Kruse FE, Naumann GO, Schlötzer-Schrehardt U. Proinflammatory cytokines are involved in the initiation of the abnormal matrix process in pseudoexfoliation syndrome/glaucoma. Am J Pathol. 2010;176: 2868-79.

6. Tzouvelekis A, Bonella F, Spagnolo P. Update on therapeutic management of idiopathic pulmonary fibrosis. Ther Clin Risk Manag. 2015;11:359-70.

7. Chupp GL, Lee CG, Jar jour N, Shim YM, Holm CT, He S, et al. A chitinase-like protein in the lung and circulation of patients with severe asthma. N Engl J Med. 2007;357:2016-27.

8. Malinda KM, Ponce L, Kleinman HK, Shackelton LM, Millis AJ. Gp38k, a protein synthesized by vascular smooth muscle cells, stimulates directional migration of human umbilical vein endothelial cells. Exp Cell Res. 1999;250:168-73.

9. Hakala BE, White C, Recklies AD. Human cartilage gp-39, a major secretory product of articular chondrocytes and synovial 
cells, is a mammalian member of a chitinase protein family. J Biol Chem. 1993;268:25803-10.

10. Shackelton LM, Mann DM, Millis AJ. Identification of a 38-kDa heparin-binding glycoprotein $(\mathrm{gp} 38 \mathrm{k})$ in differentiating vascular smooth muscle cells as a member of a group of proteins associated with tissue remodeling. J Biol Chem. 1995;270:13076-83.

11. Rehli M, Krause SW, Andreesen R. Molecular characterization of the gene for human cartilage gp-39(CHI3L1), a member of the chitinase protein family and marker for late stages of macrophage differentiation. Genomics. 1997;43:221-5.

12. Rathcke CN, Vestergaard H. YKL-40-an emerging biomarker in cardiovascular disease and diabetes. Cardiovasc Diabetol. 2009;8:61.

13. Nielsen AR, Plomgaard P, Krabbe KS, Johansen JS, Pedersen BK. IL-6, but not TNF- $\alpha$, increases plasma YKL- 40 in human subjects. Cytokine. 2011;55:152-5.

14. Michelsen AE, Rathcke CN, Skjelland M, Holm S, Ranheim T, Krohg-Sørensen K, et al. Increased YKL-40 expression in patients with carotid atherosclerosis. Atherosclerosis. 2010;211:589-95.

15. Kim HM, Lee BW, Song YM, Kim WJ, Chang HJ, Choi DHP, et al. Potential association between coronary artery disease and the inflammatory biomarker YKL-40 in asymptomatic patients with type 2 diabetes mellitus. Cardiovasc Diabetol. 2012;11:84.

16. Väänänen T, Koskinen A, Paukkeri EL, Hämäläinen M, Moilanen $\mathrm{T}$, Moilanen E, et al. YKL-40 as a novel factor associated with inflammation and catabolic mechanisms in osteoarthritic joints. Mediat Inflamm. 2014;2014:215140.

17. Johansen JS. Studies on serum YKL-40 as a biomarker in diseases with inflammation, tissue remodelling, fibroses and cancer. Dan Med Bull. 2006;53:172-209.

18. Seo J, Ahn Y, Zheng Z, Kim BO, Choi MJ, Bang D, et al. Clinical significance of serum YKL-40 in Behçet disease. Br J Dermatol. 2016;174:1337-44.

19. Yildirim Z, Yildirim F, Uçgun NI, Sepici-Dinçel A. The role of the cytokines in the pathogenesis of pseudoexfoliation syndrome. Int J Ophthalmol. 2013;6:50-53.

20. Garweg JG, Zandi S, Pfister IB, Skowronska M, Gerhardt C. Comparison of cytokine profiles in the aqueous humor of eyes with pseudoexfoliation syndrome and glaucoma. PLoS One. 2017;12:e0182571.

21. Sarenac Vulovic TS, Pavlovic SM, Zdravkovic NS. Proinflammatory Cytokines Induce XFG Development. Ocul Immunol Inflamm. 2016;24:671-7.

22. Sarenac Vulovic TS, Pavlovic SM, Jakovljevic VL, Janicijevic $\mathrm{KB}$, Zdravkovic NS. Nitric oxide and tumour necrosis factor alpha in the process of pseudoexfoliation glaucoma. Int J Ophthalmol. 2016;9:1138-42.

23. Rathcke CN, Vestergaard H. YKL-40, a new inflammatory marker with relation to insulin resistance and with a role in endothelial dysfunction and atherosclerosis. Inflamm Res. 2006;55:221-7.

24. Hirano T, Matsuda T, Nakajima K. Signal transduction through gp130 that is shared among the receptors for the interleukin 6 related cytokine subfamily. Stem Cells. 1994;12:262-77.

25. Påhlman LI, Jögi A, Gram M, Mori M, Egesten A. Hypoxia down-regulates expression of secretory leukocyte protease inhibitor in bronchial epithelial cells via TGF- $\beta 1$. BMC Pulm Med. 2015; $15: 19$

26. Kucur M, Isman FK, Karadag B, Vural VA, Tavsanoglu S. Serum YKL- 40 levels in patients with coronary artery disease. Coron Artery Dis. 2007;18:391-6.
27. Wang Y, Ripa RS, Johansen JS, Gabrielsen A, Steinbruchel DA, Friis T, et al. YKL-40 a new biomarker in patients with acute coronary syndrome or stable coronary artery disease. Scand Cardiovasc J. 2008;42:295-302.

28. Celik C, Abali R, Guzel S, Bastu E, Kucukyalcin V, Yilmaz M. Elevated circulating levels of YKL-40 are a marker of abnormal glucose tolerance in women with polycystic ovary syndrome. Clin Endocrinol (Oxf). 2012;77:893-7.

29. Mitchell P, Wang JJ, Smith W. Association of pseudoexfoliation syndrome with increased vascular risk. Am J Ophthalmol. 1997; 124:685-7.

30. Schlötzer-Schrehardt UM, Koca MR, Naumann GO, Volkholz H. Pseudoexfoliation syndrome. Ocular manifestation of a systemic disorder?. Arch Ophthalmol. 1992;110:1752-6.

31. Gonen KA, Gonen T, Gumus B. Renal artery stenosis and abdominal aorta aneurysm in patients with pseudoexfoliation syndrome. Eye (Lond). 2013;27:735-41.

32. Praveen MR, Shah SK, Vasavada AR, Diwan RP, Shah SM, Zumkhawala BR, et al. Pseudoexfoliation as a risk factor for peripheral vascular disease: a case-control study. Eye (Lond). 2011;25:174-9.

33. Türkyılmaz K, Öner V, Kırbas A, Sevim MS, Sekeryapan B, Özgür G, et al. Serum YKL-40 levels as a novel marker of inflammation and endothelial dysfunction in patients with pseudoexfoliation syndrome. Eye (Lond). 2013;27:854-9.

34. van Kooij B, Rothova A, Rijkers GT, de Groot-Mijnes JD. Distinct cytokine and chemokine profiles in the aqueous of patients with uveitis and cystoid macular edema. Am J Ophthalmol. 2006; $142: 192-4$.

35. Ling H, Recklies AD. The chitinase 3-like protein human cartilage glycoprotein 39 inhibits cellular responses to the inflammatory cytokines interleukin-1 and tumour necrosis factoralpha. Biochem J. 2004;380:651-9.

36. Johansen JS, Lottenburger T, Nielsen HJ. Diurnal, weekly, and long-time variation in serum concentrations of YKL-40 in healthy subjects. Cancer Epidemiol Biomark Prev. 2008;17:2603-8.

37. Knudsen LS, Hetland ML, Johansen JS, Skjødt H, Peters ND, Colic A, et al. Changes in plasma IL-6, plasma VEGF and serum YKL-40 during Treatment with Etanercept and Methotrexate or Etanercept alone in Patients with Active Rheumatoid Arthritis Despite Methotrexate Therapy. Biomark Insights. 2009;4:91-95.

38. Gerin F, Sener U, Erman H, Yilmaz A, Aydin B, Armutcu F, et al. The effects of quercetin on acute lung injury and biomarkers of inflammation and oxidative stress in the rat model of sepsis. Inflammation. 2016;39:700-5.

39. Esteghamati A1, Rezvani S, Khajeh E, Ebadi M, Nakhjavani M, Noshad S. Comparative effects of metformin and pioglitazone on YKL-40 in type 2 diabetes: a randomized clinical trial. J Endocrinol Invest. 2014;37:1211-8.

40. Kunz LI, van't Wout EF, van Schadewijk A, Postma DS, Kerstjens HA, Sterk PJ, et al. Regulation of YKL-40 expression by corticosteroids: effect on pro-inflammatory macrophages in vitro and its modulation in COPD in vivo. Respir Res. 2015;16:154.

41. Zhang W, Murao K, Zhang X, Matsumoto K, Diah S, Okada M, et al. Resveratrol represses YKL-40 expression in human glioma U87 cells. BMC Cancer. 2010;10:593.

42. Rakic JM, Lambert V, Deprez M, Foidart JM, Noël A, Munaut C. Estrogens reduce the expression of YKL-40 in the retina: implications for eye and joint diseases. Invest Ophthalmol Vis Sci. 2003; 44: 1740-6. 